
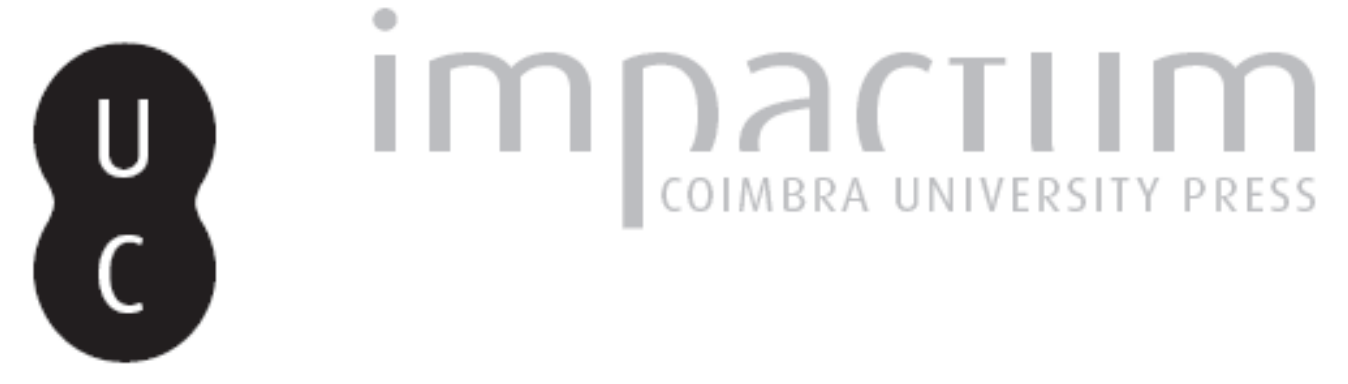

\title{
Los fantasmas del Alcázar
}

Autor(es): $\quad$ Gómez-Pantoja, Joaquín

Publicado por: Imprensa da Universidade de Coimbra

URL persistente:

URl:http://hdl.handle.net/10316.2/45365

DOI:

DOI:https://dx.doi.org/10.14195/1647-8657_40_9

Accessed : $\quad$ 26-Apr-2023 14:17:40

A navegação consulta e descarregamento dos títulos inseridos nas Bibliotecas Digitais UC Digitalis, UC Pombalina e UC Impactum, pressupõem a aceitação plena e sem reservas dos Termos e Condições de Uso destas Bibliotecas Digitais, disponíveis em https://digitalis.uc.pt/pt-pt/termos.

Conforme exposto nos referidos Termos e Condições de Uso, o descarregamento de títulos de acesso restrito requer uma licença válida de autorização devendo o utilizador aceder ao(s) documento(s) a partir de um endereço de IP da instituição detentora da supramencionada licença.

Ao utilizador é apenas permitido o descarregamento para uso pessoal, pelo que o emprego do(s) título(s) descarregado(s) para outro fim, designadamente comercial, carece de autorização do respetivo autor ou editor da obra.

Na medida em que todas as obras da UC Digitalis se encontram protegidas pelo Código do Direito de Autor e Direitos Conexos e demais legislação aplicável, toda a cópia, parcial ou total, deste documento, nos casos em que é legalmente admitida, deverá conter ou fazer-se acompanhar por este aviso.

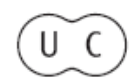


UNIVERSIDADE DE COIMBRA

FACULDADE DE LETRAS

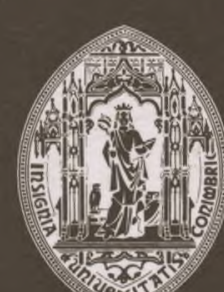

CONIMBRIGA

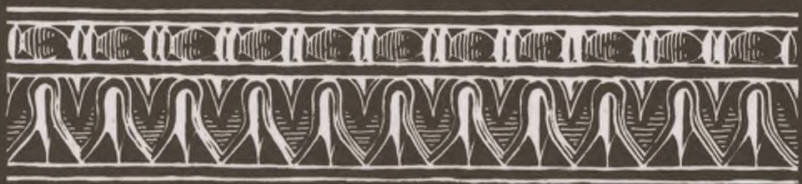

VOLUME XL - 2001 


\section{JOAQUín GÓMEZ-PANTOJA}

Profesor de Historia Antigua

Departamento de Historia I y Filosofía. Univ. de Alcalá

E- 28801 Alcalá de Henares

gomez.pantoja@uah.es

\section{LOS FANTASMAS DEL ALCÁZAR}

"Conimbriga" XL (2001) p. 283-319

Resumen: Una fuente de comienzos del siglo XIX asegura haber visto en el célebre Alcázar de Segovia tres inscripciones latinas de las que ofrece descripción y texto. Por razones no aparentes, esas tres piezas no figuran en CIL II, pero recientemente R. Knapp ha rescatado su memoria, atribuyéndoles procedencia segoviana. Este trabajo argumenta en contra de ese origen y sugiere que debieron ser traídas a Segovia con motivo de la fundación del Colegio de Artillería. Por razones estilísticas y formularias es muy posible que las inscripciones procedan de la Bética o de la Lusitania meridional.

ABStRACT: An early 19th century Spanish source reported about three Latin inscriptions standing at the Royal Artillery College, then housed in the famous Alcázar de Segovia. For unknown reasons, Htibner failed to register them in CIL and were recently rescued from oblivion by R. Knapp. This paper argues against the proposed local origin of the stones; instead, other data and the formulae strongly suggest some people teaching at the Military Academy carried them, probably from somewhere in Baetica or southern Lusitania.

Conimbriga, 40 (2001) 281-317 
(Página deixada propositadamente em branco) 


\section{LOS FANTASMAS DEL ALCÁZAR}

El buen hacer de un trasgo se mide por la mayor o menor intensidad del sobresalto que provoca, pues es sabido que las manifestaciones fantasmagóricas se caracterizan sobre todo por lo inopinadas y extemporáneas que resultan. Cuándo o ante quién se aparece un espíritu es, por lo que se ha podido averiguar, cuestión de su real gana $\mathrm{y}$, al parecer esa es la única regla que los gobierna. En consecuencia, la figura del alma en pena que actúa tan puntual, rutinaria y organizadamente como don Emmanuel Kant puede que exista en la creación literaria, pero no en la vida real. Al contrario, quedar con un lémur a hora fija exige poderosos conjuros o el auxilio de espectros más fuertes que obliguen al informal a presentarse a la cita. De ahí que si se habla tan poco de los fantasmas - algunos dudan incluso de su existencia -, ello es únicamente achacable a su impuntualidad e inconstancia, porque nunca acuden dos veces al mismo sitio y a hora fija.

Los epigrafistas, sin embargo, pertenecemos a un gremio que no hace ascos al trato con espectros $y$ otros seres paranormales. Quienes mayormente coleccionan y descifran epitafios $\mathrm{y}$ otros letreros fúnebres, que es un material muy adecuado para las emanaciones ectoplásmicas, no pueden sino asumir el riesgo de alguna que otra experiencia espeluznante. Todavía corre en boca de muchos el relato del encuentro memorable que dos colegas, en comisión epigráfica por Galicia, tuvieron con la Santa Compaña; y, en tiempos más recientes, está en los papeles cómo otro se tropezó con un bodeguero fantasma. ${ }^{1}$

No debe extrañar, pues, que se hable aquí de apariciones y duendes, aunque he de advertir que sólo en sentido figurado, porque resulta impropio predicar esa condición de objetos inanimados. En puridad,

1 A. Fernández Guerra y F. Fita, Recuerdos de un viaje á Santiago de Galicia, Madrid, 1880; A. U. Stylow, Missing the point(s). Un bodeguero fantasma (a propósito de CIL II 5356), Anuari di Filologia. Studia graeca et latina, 18, 1995 p. 191-199.

Conimbriga, 40 (2001) 281-317 
trataré de tres lápidas latinas de las que ni siquiera estoy seguro que todas tuvieran relación con entierros pero que, sin embargo, se comportan como si fueran espantajos y visiones, porque su imprevisible aparición y desvanecimiento provocaron la sorpresa y la confusión de los testigos, que se manifestaron inseguros sobre lo que vieron o de dónde provenía. Finalmente, de forma accesoria pero no intrascendente, el fenómeno ocurrió en el Alcázar de Segovia, que pertenece a esa categoría de edificios que uno espera aloje muchos fantasmas en ejercicio.

Es de bien nacidos ser agradecidos y por ello manifiesto mi deuda con Agustina Gómez-Pantoja, Víctor Pérez Yuste y Carlos Gómez de la Fuente, de Segovia, por ayudarme a indagar quién fue Felice Gazzola; y con Leonard Curchin (University of Waterloo, Ontario), Félix García Palomar (Madrid), Gian Lúea Gregori (Universitá La Sapienza, Roma), Patrick Le Roux (Université de Haute Bretagne, Rennes), Armin U. Sty low (Komm. f. Alte Geschichte u. Epigraphik des DAI, München / Centro CIL II-Alcalá) y José-Vidal Madruga (Monterrubio de la Serena, Extremadura), porque sus comentarios mejoraron la forma en que está escrito este trabajo y sus sugerencias contribuyeron a descubrir el posible origen de las inscripciones del Alcázar.

\section{El testimonio del vidente}

Nuestro relato comienza en Segovia en los años inmediatamente posteriores a la Francesada, cuando un canónigo de la catedral, don Andrés Gómez de Somorrostro, dio a la imprenta en Madrid una erudita e informativa memoria sobre el Acueducto y las demás antigüedades romanas existentes en su ciudad. ${ }^{2}$ En ella cuenta que en el Gabinete de Mineralogía del Laboratorio Químico del Real Colegio de Artillería de Segovia, entonces aún sito en el Alcázar, había tres inscripciones romanas, de las que ofrece sus textos y unas sumarias descripciones. Por razones no aparentes a primera vista, ninguna de las demás autoridades que se ocuparon luego de la epigrafía o las

2 A. Gómez de Somorrostro, El Acueducto y otras antigüedades de Segovia Madrid, 1820, pp. 233-234. Existe una segunda edición ampliada por un sobrino y homónimo del autor, que apareció en Madrid en 1861. Mis citas corresponden a la edición original, que fue reimpresa en Segovia en 1975.

Conimbriga, 40 (2001) 281-317 
antigüedades segovianas volvió a mencionar esas inscripciones. No deja, por lo tanto, de constituir una agradable sorpresa que un reciente catálogo de las inscripciones romanas de esa ciudad haya recuperado los datos de Somorrostro. ${ }^{3}$ Dada la singularidad del testimonio del canónigo y para facilitar futuras referencias, ha parecido oportuno reproducirlo tal cual en el primer apéndice, del cual y con algunas diferencias respecto a lo dicho por Knapp, se ha trascrito el contenido de esas lápidas según el modelo moderno de notación epigráfica.

La primera lápida, descrita por Somorrostro como "una pilastra de mármol" y cuyas dimensiones en antiguas medidas castellanas las convirtió Knapp a su equivalente métrico $(60 \times 20 \times 40 \mathrm{~cm})$, decía esto: ${ }^{4}$

\author{
[D(is)] m(anibus) [s(acrum)]. \\ Fabi[a] Dio- \\ nysia, an(norum) \\ $\mathrm{XVII} \bullet \mathrm{m}($ ensium $) \bullet \mathrm{III} \bullet \mathrm{d}($ ierum $) \bullet \mathrm{X} \bullet$, \\ 5- hic $\bullet \operatorname{sit}\ulcorner\mathrm{a}\urcorner \bullet e s t$. \\ Dionysiodo- \\ rus•, Restitu- \\ ta・, filiae $\bullet$ piis- \\ sime fecerun- \\ 10- $\ulcorner\mathrm{t}\urcorner \bullet \mathrm{s}($ it $)\ulcorner\mathrm{t}\urcorner \cdot($ ibi $) \bullet \mathrm{t}($ erra $) \bullet l e v i s \bullet$
}

R. 1 :::::: M Somorrostro, que Knapp interpretó como [D(is)] $M$ (anibus) $\backslash$ pienso, en cambio que ese recurso tipográfico indicaba que había rasgos a ambos lados de la $\mathrm{M}$ y que éstos se leían malamente. Knapp.

R. 2: - FABI, Somorrostro, correctamente completado por

R. 5: SITVS, Somorrostro, quien advierte que dejó esta línea tal y como la tenía en su calco, a pesar de ser consciente de los "defectos que se advierten en la ortografía y la concordancia"; la enmienda es de Knapp.

R. 10: H-S-H-T* LEVIS, Somorrostro, aplicando lo arriba dicho; las enmiendas, de nuevo, son de Knapp. Stylow me sugiere que quizá, en 1.9 se escribió fecerunt completo, con /NT/ en nexo, lo que concordaría, desde el punto de vista de la ordenación del texto, con la obser-

3 R. C. Knapp, Latin Inscriptions from Central Spain, Berkeley, 1992, pp. 328-331.

4 Knapp, op. cit., pp. 224-225, n. 247 = Hispania Epi graphica (= HEp) 4, 616. 
vación de Somorrostro que este renglón se escribió "en la media caña", i.e., en la moldura. Sin embargo, mantengo la enmienda de Knapp por ajustarse mejor a lo transmitido; nótese la confusión de /H/ por /T/.

La segunda pieza la describe Somorrostro en todo igual a la primera salvo en sus dimensiones, que Knapp 5 calcula en torno a $30 \mathrm{x}$ 20 x $40 \mathrm{~cm}$; la trascripción de la misma es del siguiente tenor:

\section{$\mathrm{D}$ (is) $\bullet \mathrm{m}$ (anibus) $\bullet$ s(acrum). \\ $\mathrm{C}$ (ornelio?) Iuliano•ann(orum) $\bullet \mathrm{XV}$ \\ Iul(ia) Helpis•mater \\ fil(io)•pientissimo•p(onendum)•c(uravit). \\ 5- $\mathrm{H}($ ic $) \bullet \mathrm{s}($ itus $) \bullet e(\mathrm{st}) \bullet \mathrm{S}($ it $) \bullet t($ ibi $) \bullet t($ erra $) \bullet l e v i s \bullet$}

R. 2: $\mathrm{C}^{\circ}$, Somorrostro, quien lee $C$ (aius); Knapp, en cambio, lo interpretó como Co(rnelius)। a mi juicio, es simplemente un artificio tipográfico para notar que el nombre está abreviado.

R. 3: IUL a HEIPIS, Somorrostro, adecuadamente corregido por Knapp, quien, sin embargo, repite error en la lectura del gentilicio y propone leer Iul[i]a Helpis.

De la última pieza, Somorrostro apenas ofrece una imprecisa descripción 6 - pedestalito de mármol para una cabeza - sin medidas, que nos deja preguntándonos si pensó que sostenía precisamente eso por el pequeño tamaño del soporte o porque confundió el corriente focus de un ara con el alojamiento del busto.

$$
\begin{aligned}
& \mathrm{C}(\text { aius }) \bullet \mathrm{Iul}(\text { ius }) \bullet \mathrm{Co}[++++++]- \\
& \mathrm{is} \bullet \mathrm{v}(\text { otum }) \bullet \mathrm{M}(\text { erito }) \mathrm{l}(\text { ibens }) \bullet \mathrm{s}(\text { olvit }) \text {. }
\end{aligned}
$$

Somorrostro transmitió el texto en un solo renglón, con una serie vertical de cuatro puntos inmediatamente antes de /IS/, que Knapp interpretó como un cambio de línea. En el primer renglón, los siete caracteres que Somorrostro no descifró, aparecen representados como lambdas, quizá porque lo que vio le recordaban la forma de esa letra griega. Por lo tanto, quizá quepa suponer que el alfabeto empleado era uno de tipo actuario o rústico.

5 Knapp, op. cit., pp. 220-221 n. $242=$ HEp 4, 615.

6 Knapp, op. cit., pp. 225 n. $248=$ HEp 4, 617. 
Knapp reconstruyó el texto como C(aius)- Iul[i]u[s]-Co ++++++ / IS $V++I S$, suponiendo que la $\mathrm{V}$ del segundo renglón posiblemente marcaba el inicio del cognomen y que las letras siguientes quizá pudieran leerse como $[p($ ius $)] \quad i(n) s(u i s)$, una posibilidad que él mismo reconoce poco convincente, por tratarse de un formulario escasamente empleado en la zona. En cambio, yo supongo que el gentilicio estaba abreviado del modo corriente, mientras que el rasgo inmediatamente posterior, interpretado por Somorrostro como una /V/ y por Knapp como parte del nombre gentil, fue quizá una hedera distinguens, pues es bien sabido que este separador de palabras puede fácilmente confundirse con una letra en textos muy erosionados. El resto del renglón contenía, a mi entender, el cognomen, del que sólo se conservaba el comienzo y el final y para el que, a guisa de ejemplo, caben estas posibles restituciones: Co[mpetal]is, Co[nsular]is; Co[nvental]is y Co[nfin]is, aunque Co[mmun]is parece la mejor alternativa no sólo por ser el nombre más corriente sino porque sus letras semiborradas pueden, efectivamente, parecerse a una serie de lambdas. ${ }^{7}$ A continuación, el rasgo que Knapp consideraba como la vocal final de un cognomen, creo que corresponde al inicio de la más corriente de las fórmulas abreviadas de ofrecimiento, lo que resulta una alternativa mucho mejor que el incongruente pius in suis en un texto que carece de cualquier otro rasgo de carácter sepulcral; y como no resulta difícil suponer al final de la segunda línea una confusión de /I/ por /L/, ello redondea el formulario votivo. La ausencia del teónimo no es obstáculo para mi hipótesis pues es bien sabido que la misma imagen que soportaba el pedestal o, simplemente, el contexto de la pieza, hacía inútil en muchas ocasiones tal mención. ${ }^{8}$

7 Respectivamente, CIL V 1142; XIV 2867 y 2961; VIII $11605=$ Z. Benzina ben Abdallah, Catalogue des inscriptions latines paiennes du Musée du Bardo, Roma, 1986, n. 66; CIL XIII 7505 y AE 1956, 165. Sobre Communis, vid. I. Kajanto, The Latin Cognomina, Helsinki, 1965, p. 256.

8 Vid. J. d'Encarnação, Omissão dos teónimos em inscrições votivas, en Studia Paleohispanica (IV Coloquio sobre Lenguas y Culturas Pre-romanas de la Península Ibérica, Vitoria 1985), Vitoria, 1987, pp. 305-310. 


\section{La controversia}

Lo dicho constituye la evidencia disponible, presentada según el canon de objetividad que exige la moderna investigación histórica. Esos datos, sin embargo, son mucho más polémicos de lo que a primera vista parece.

En primer lugar, y como ya se ha dicho, en los casi dos siglos transcurridos entre Somorrostro y Knapp, ninguno de los otros autores que se han ocupado de la epigrafía o las antigüedades segovianas, volvieron a mencionar tales piezas. En Abril de 1860, un observador tan experimentado como Emil Hübner visitó Segovia para comprobar personalmente la situación de las lápidas reportadas por Somorrostro y de lo completo y concienzudo de su examen resultó la localización de 17 de las 29 descritas por el canónigo; sin embargo, en el capítulo correspondiente de CIL II no se mencionan ninguna de las tres inscripciones que nos ocupan. ${ }^{9}$ La misma extrañeza provoca su ausencia en las relaciones posteriores de eruditos españoles, como Quadrado y Fita, ${ }^{10}$ que estaban ciertamente familiarizados con los escritos del canónigo anticuario.

En definitiva, de la existencia de las inscripciones no hay otra constancia que el propio relato de Somorrostro. En 1987, por encargo de Knapp, escribí a la Academia de Artillería interesándome por el paradero de las piedras y me contestaron que no les constaba; un año después, el propio Knapp repitió personalmente la gestión, con el mismo resultado. El estudioso americano achaca la pérdida - y el consecuente silencio de otros anticuarios - al fuego que consumió el Alcázar en 1862, que obligó al traslado del Colegio de Artillería a otra sede y condenó al castillo-palacio a medio siglo de abandono y ruina. Sin embargo, esta explicación es muy improbable porque el lugar donde Somorrostro vio las inscripciones, el Laboratorio de Química, nunca estuvo bajo los techos del Alcázar, precisamente en evitación de peligrosos incendios y explosiones. Cuando en 1786 se trajo al químico francés Louis Proust ${ }^{11}$ para crear y dirigir el Laboratorio, se le buscó

9 CIL II pp. 379 y 926.

10 J. M. Quadrado, España, Sus monumentos y sus artes - Salamanca, Avila y Segovia, Barcelona, 1884; y F. Fita, Segovia: Monumentos y documentos inéditos, Boletín de la Real Academia de la Historia 13, 1888, pp. 309-317.

11 Sobre Proust y su trabajo, vd. J. Sarrailh, La España Ilustrada de la segunda mitad del siglo XVIII, Madrid, 1957, p. 494. Más bibliografía, incluyendo referencias

Conimbriga, 40 (2001) 281-317 
acomodo fuera de lo que era propiamente el Real Colegio; y cuando se decidió darle una sede propia y definitiva, la llamada Casa de la Química, ésta se levantó aislada del edificio principal, en cuyo Patio de Armas aún sigue. Resulta, pues, improbable que las tres inscripciones romanas del Gabinete de Mineralogía - que quizá estaban allí en razón de su interés petrológico - fueran afectadas directamente por el fuego que arruinó y consumió el edificio colindante.

Pero el problema más serio que plantean estos epígrafes es el de su incongruente situación en Segovia. Somorrostro obvió decir dónde se encontraron y aunque ese silencio puede, efectivamente, entenderse como una implícita afirmación de su origen segoviano, son muchos otros los indicios conducentes a juzgarlos como forasteros. Knapp señaló algunos de ellos y los examinó con cierto detalle: el material del soporte, la onomástica de los personajes mencionados y el empleo de un formulario poco corriente en las otras inscripciones de la zona. Pero hay que volver sobre la cuestión porque, como se verá, mi conclusión es radicalmente opuesta a la obtenida por el estudioso americano.

Ya se ha notado que las tres lápidas estaban labradas en mármol, que es un material poco usado en las inscripciones romanas del interior de la península Ibérica y nada frecuente en la Meseta Norte, donde lo corriente fue el recurso a las piedras locales, generalmente areniscas y calizas, aunque en aquellos lugares donde aflora el zócalo paleozoico también se emplearon granitos, conocidos en Segovia como "piedra cárdena". De las 74 lápidas antiguas halladas en ese lugar y sus alrededores, Knapp señala que 37 son de granito y 31 de caliza; de otras cuatro se desconoce la calidad de la piedra y de las dos restantes, una es musivaria y la otra de mármol. Esta distribución justifica sobradamente las sospechas de forastería de las tres piedras del Laboratorio de Química del Real Colegio de Artillería, pero no las valida, porque se trata de un argumento ex silentio:ya está atestiguado un ejemplo de uso de mármol y sólo hace falta tiempo para que aparezcan otros. ${ }^{12}$

al discurso del propio Proust en la inauguración del Laboratorio de Química, en M. D. Herrero Fernández-Quesada, La enseñanza militar ilustrada. El Real Colegio de Artillería de Segovia, Segovia, 1990, pp. 174-182.

12 Somorrostro, op. cit., pp. $140-143$ n. $22=$ CILII2752 = Knapp, op. cit., pp. 240-241 n. 263 , con foto $=\operatorname{HEp~4,~629:~debe~descartarse~cualquier~duda~sobre~la~proce-~}$ dencia de la lápida, que fue descubierta a comienzos del siglo XIX en el interior de una iglesia románica del siglo XII, en un lugar donde podía llevar centurias.

Conimbriga, 40 (2001) 281-317 
Otro rasgo sospechoso es la nomenclatura de los personajes mencionados en las tres piezas en discusión. Dionysia, Dionysiodorus y Helpis no sólo son nombres helenizantes que contrastan con los habituales en la epigrafía local, de raigambre hispana o adaptaciones al latín de ésta, sino que uno de ellos - Dionysodorus -, es tan infrecuente en Occidente que, por lo que yo sé, casi sólo está atestiguado hasta ahora en Roma... y en Segovia. ${ }^{13}$

Sin embargo, de nuevo debe darse la razón a Knapp sobre el valor probatorio de este indicio, que queda anulado por la existencia de otros personajes de nombre griego - posiblemente, de origen libertino -, en la misma Segovia o en localidades vecinas. ${ }^{14}$ Finalmente, un tercer rastro de forastería es el inusual formulario de las inscripciones: en una, la compleja fórmula mencionando la edad del finado en años, meses y días es privativa de sitios muy concretos de las provincias hispanas, todos ellos fuertemente sometidos a influencia externa; ${ }^{15}$ en otra,

13 Vd. H. Solin, Die griechische Personennamen in Rom. Ein Namenbuch, Berlín, 1982, pp. 43-44, que recoge los ejemplos de la Urbe (CIL VI 29557, 3 y 5; 32480 y 21213 (Dionisiodorus) y otros casos posteriores). Fuera de la Urbs, y excluyendo el caso segoviano en discusión (vd. J. M. Abascal, Los nombres personales en las inscripciones latinas de Hispania, Murcia, 1994, p. 344 y A. Lozano, Die grieschichen Personennamen aufder iberischen Halbinsel (Beitráge zur Namenforschung, 49), Heidelberg, 1998, p. 74), sólo he sido capaz de encontrar un ejemplo de su uso en las provincias occidentales (CIL V 8124,2), aunque baso mi aserto no en un expolio sistemático sino sólo en la consulta de los índices de A. Mócsy, R. Feldmann, E. Marton y M. Szilágyi, Nomenclator provinciarum Europae Latinarum et Galliae Cisalpinae cum indice inverso, Budapest, 1983, s.v.; de B. Lorincz, Onomasticon provinciarum Europae Latinarum, vol. II: Cabalicus-Ixus, Viena, 1999; y en la rebusca en las ciento y pico mil inscripciones contenidas conjuntamente en las bases de datos de Frankfurt (http://www.rz.uni-frankfurt.de/ clauss) y del Epigraphische Datenbank de Heidelberg (http://www.rzuser.uni-heidelberg.de/ f56/edh/search.html).

14 Knapp, op. cit. , p. 330.

15 Tarraco, donde constituye un vulgarismo (vid. G. Alfóldy, Die rómischen Inschriften von Tarraco, Berlin, 1975, n. 180, 184, 232, 499, 567, 589, 593, 632, 639, 641,652, 671, 683, 686, 916, 953, 964, 973, 979, 998, 999 у 1009); Corduba (CIL II/2-7, 420, 421, 430, 549 y 654); Barcino (G. Fabré, M. Mayer e I. Rodá, Inscriptions romaines de Catalogne. IV. Barcino, París. 1997, nn. 160 y 205) y en lugares sueltos del conventus Astigitanus (CIL II/2-5, 325, 870 y 1010) y de la costa levantina (CIL II/2-14, 600; J.M. Abascal y S. Ramallo, La ciudad de Carthago Nova, III: La documentación epigráfica, Murcia. 1997, n. 115; y Fabré, M. Mayer e I. Rodá, Inscriptions romaines de Catalogue. II. Lérida, París. 1985, n. 10). Fuera de esta área altamente romanizada, sólo he encontrado representado este manierismo en Emerita (CIL II 525 y 541).

Conimbriga, 40 (2001) 281-317 
Knapp señalaba la expresión pius in suis, pero como hemos visto, quizá no haya lugar para esa suposición.

Tras considerar todos estos indicios, Knapp se inclina a juzgar de origen local las dos primeras inscripciones reportadas por Somorrostro y otrora conservadas en la Academia de Artillería; para la tercera, mantiene sus reservas, principalmente por la insólita forma del soporte. Aunque algunos de esos indicios podrían tener mayor peso excluyente del que Knapp optó por darles, caben pocas dudas de que es legítimo resolver el non liquet en los términos en que él los plantea. Sin embargo, al examinar de nuevo la cuestión, creo que las sospechas sobre el origen de las piezas no sólo se sustentan en lo infrecuente de la onomástica o en formularios desusados sino que hay otros indicios no tenidos en cuenta hasta ahora.

El primer lugar, debe examinarse la cuestión de la forma de las lápidas. Somorrostro dice de dos de ellas que tenían "la figura de pilastra" y aunque es dudoso que emplease ese término en el preciso sentido técnico que ahora se usa, ${ }^{16}$ las medidas que proporciona corresponden a lastras estrechas, varias veces más altas que anchas y, presuntamente, de forma ortogonal. La pilastra como soporte epigráfico fue relativamente común en Italia ${ }^{17}$, pero infrecuentísima en la Península Ibérica, incluso en aquellas zonas como la Bética o las regiones mediterráneas más expuestas a las influencias y los gustos foráneos. ${ }^{18}$ Pero la descripción de Somorrostro, especialmente si se nota lo que dice acerca de las molduras en la parte superior e inferior, también puede cuadrar con las características del ara funeraria, un soporte que imita la forma de los exvotos divinos y que fue relativamente corriente en Hispania.

El mayor argumento en favor de la forastería de las tres lápidas se deduce de la propia presentación que de ellas hace Somorrostro, un detalle que a Knapp se le pasó por alto u omitió mencionar: si el hallazgo sucedió en Segovia, debe entonces explicarse por qué el canónigo relegó estos epígrafes a un apéndice de cuyo contenido se advierte que

16 Vid. I. de Stefano Manzella, Mestiere di epigrafista. Guida alia schedatura del materiale epigráfico lapideo, Roma, 1987, p. 79.

17 Vid. por ejemplo II Lapidario Zeri di Mentana, Roma, 1982, p. 147 n. 71; p. 236 n. 152 ; y p. 407 n. 344.

18 Vid. A.U. Stylow, Los inicios de la epigrafía latina en la Bética. El ejemplo de la epigrafía funeraria, en F. Beltrán Lloris (edit. ), Roma y el nacimiento de la cultura epigráfica en Occidente, Zaragoza, 1995, pp. 224-225. 
hay, además de las inscripciones que se pusieron en el capitulo $4^{\circ}$ de la segunda parte del Discurso [i.e. la lista de treinta epígrafe que Somorrostro vio él mismo o describió a partir de otros], las siguientes, que ha parecido oportuno reunir en este Apéndice, aunque algunas son pertenecientes a los siglos medios, y otras muy modernas, que tal vez desaparecerán, y no quedará más memoria de ella que la que se da en esta colección.

A mi juicio, esa exposición de motivos indica paladinamente que las tres inscripciones existentes en el Gabinete de Mineralogía del Laboratorio Químico del Real Colegio de Artillería no habían sido encontradas en Segovia y me atrevo a sospechar que a la misma conclusión debió de llegar Hübner, pues de otro modo es imposible justificar por qué nada se dice de ellas en el volumen hispánico del Corpus Inscriptionum Latinarum: si el sabio alemán pensó que se trataba de alienae in Hispania servatae, la praxis habitual exigía la remisión de los datos a la Academia Berlinesa, a la espera de que fueran de utilidad para otro redactor, lo que en este caso no parece haber sucedido, pues he sido incapaz de encontrar ninguna referencia a ellas en otros volúmenes del CIL. ${ }^{19}$

Hay, además, fuertes razones que llevan a pensar que ninguna de las lápidas en cuestión estaban en Segovia antes de 1760. Baso mi aserto en un dato que ni Hübner ni Knapp reflejan pero de notable utilidad explicativa en el caso que nos ocupa. Me refiero a la existencia de un manuscrito epigráfico, propiedad de Somorrostro, que contenía "una colección....hecha con mucha exactitud y diligencia en el año de 1760." 20 Como el canónigo segoviano no identifica al autor ni da pistas que permitan desvelar su anonimato, desconozco el actual paradero de ese documento, si es que aún existe. Sin embargo, el contenido y algunas características de esa relación epigráfica pueden deducirse de lo escrito por Somorrostro: por ejemplo, de la afirmación de que "ésta (la vigésima segunda lápida de su catálogo) y las siguientes inscrip-

19 Un ejemplo de este proceder lo ofrecen las inscripciones de origen urbano que Hübner vió en Madrid; algunas aparece reflejadas en su Die Antike Bildwerke in Madrid, Berlin, 1862, pero otras deben rastrearse en los diversos volúmenes del CIL, vd. por ejemplo CIL VI 12037. Stylow, en cambio, piensa que Hübner no vio estas inscripciones; de otro modo hubieran sido probablemente recogidas, salvo que le constara claramente al editor su origen.

20 Somorrostro, op. cit., p. 128.

Conimbriga, 40 (2001) 281-317 
dones son las que se han descubierto y añadido á la colección que se formó en $1760 ",{ }^{21}$ se deduce que la fuente anónima contenía 21 epígrafes, de los cuales cinco (cuatro afirma Somorrostro por error) corresponden a los descritos por un humanista del siglo XVII, Diego de Colmenares, ${ }^{22}$ mientras que los otros dieciséis debieron ser descubiertos con posterioridad. El Anónimo ilustró su relación con dibujos que el canónigo segoviano juzgaba excelentes y que en muchas ocasiones, le permitieron corregir y completar la lectura de piezas que en su tiempo apenas eran visibles; así, por ejemplo, de la inscripción colocada bajo el número 11 en su relación, Somorrostro afirma que es apenas visible pero ofrece la lectura de siete renglones, sin duda sacados del dibujo de su predecesor.

De la comparación de la forma y el contenido de las veintiuna primeras schedae de la colección de Somorrostro con las nueve restantes, salta a la vista que, en estas últimas, las descripciones de su forma, su colocación y las circunstancias del hallazgo son más detalladas y enjundiosas que en las primeras, para las cuales - a excepción de las cinco ya dadas a conocer por Colmenares, que admiten una cierta discusión erudita -, apenas se dan otros detalles que su colocación topográfica y el mayor o menor deterioro sufrido entre la versión de 1760 y lo que Somorrostro pudo ver.

De todos estos indicios se deduce que el anónimo autor de la colección de 1760 apenas fue capaz de encontrar otra información sobre los epígrafes que la discusión generada por los hallazgos de Colmenares. Además, resulta evidente que el fuerte del manuscrito eran sus dibujos, en los que Somorrostro confió plenamente para descifrar algunos epígrafes que eran ya ilegibles en su época; esta dependencia permite reconstruir la lista de 21 inscripciones contenidas en el manuscrito de 1760, concordándola con otros repertorios antiguos y modernos (vid Apéndice II).

\section{Algunas explicaciones}

Tenemos, pues, unas inscripciones que su editor princeps no quiso describir junto a los epígrafes de Segovia, que muy seguramente

${ }^{21}$ Somorrostro, op. cit.,p. 140.

22 Diego de Colmenares, Historia de la insigne ciudad de Segovia, dada a la luz en 1637 (hay un facsímil de 1969).

Conimbriga, 40 (2001) 281-317 
aún no estaban allí en 1760 y que otros criterios de más aleatoria eficacia señalan también como foráneas, quizá incluso de origen extrapeninsular.

Debe averiguarse, por tanto, quién, cómo y cuándo pudo importarlas y, sobre todo, de dónde; dado que los propios documentos guardan silencio sobre estos extremos, la respuesta hay que buscarla de modo indirecto, extrayéndola de los rasgos externos de los propios epígrafes y combinándola con la búsqueda del individuo, o individuos, que pudieron llevarlos a Segovia en la última mitad del siglo XVIII. Aunque no es probable que ninguna de las dos encuestas resuelva fehacientemente los interrogantes planteados, cabe quizá esperar que la confluencia de ambas estreche tanto el ámbito de la incógnita que su resultado pueda tenerse como la más probable y lógica solución.

Entre quienes pudieron trasladar a Segovia a mediados del siglo XVIII las inscripciones que nos ocupan, hay dos grupos de candidatos obvios. El primero lo forman las personas atraídas a la ciudad castellana con motivo de la fundación en 1764 del Real Colegio de Artillería y el segundo los cortesanos que acudían cada verano al Real Sitio de San Ildefonso de la Granja.

Es bien conocido que desde fines del siglo XVII comenzó a existir en Europa una fuerte complicidad entre los militares y los espíritus más ilustrados del momento, en parte debido a la progresiva tecnificación de la guerra y al uso bélico de los nuevos conocimientos; en parte por el redescubrimiento - los romanos ya lo sabían - de que el liderazgo en combate exigía, en igual medida, virtudes castrenses y civiles; y en parte por razón de la Realpolitik del momento: el fortalecimiento y centralismo de las monarquías europeas necesitaba ejércitos eficaces, leales y lo suficientemente numerosos como para imponerse al contrario pero sin acogotar al Tesoro real. Estas necesidades modificaron las bases de la educación militar, especialmente en aquellas nuevas ramas de la milicia que exigían méritos distintos al valor o la habilidad física. De este modo, el hijo de noble familia, educado desde niño para la guerra a base de orgullo de casta, experiencia familiar y la práctica de la caza, la justa y la cetrería, fue sustituido por el cadete formado en instituciones regladas y patrocinadas por el monarca, cuya finalidad era convertir individuos de la baja nobleza o de la burguesía en oficiales de las nuevas armas del Rey, la Artillería y los Ingenieros. La adquisición de sólidos conocimientos de cálculo, geometría, dibujo y química iba encaminada al dominio del tiro, la liga de metales, la

Conimbriga, 40 (2001) 281-317 
mezcla de pólvoras y el arte de hacer y deshacer fortificaciones. A los futuros oficiales se les inculcaba también la necesaria disciplina y la moral militar mediante la ejercitación del orden cerrado y la lectura de la Historia Sagrada y de las biografías de los grandes héroes grecorromanos, a las que se le atribuía un gran valor ejemplarizante. ${ }^{23}$ En España, la reforma que introdujo el nuevo paradigma militar se debe en gran medida a Carlos III, que estableció el ejército de Nueva Planta, reorganizó la Real Artillería y se sirvió de los Ingenieros militares como agentes de las iniciativas reales para el fomento del país. ${ }^{24}$

Como buenos educandos en el espíritu de las Luces, los militares españoles manifestaron con frecuencia una especial sensibilidad y curiosidad ante los edificios y objetos procedentes de lo que entonces se imaginaba el esplendoroso pasado de griegos y romanos. Aunque no se ha hecho un estudio global de ello, la documentación disponible ofrece bastantes ejemplos, de los que he seleccionado algunos. En 1747, el Marqués de la Ensenada envió al ingeniero Carlos Luxán, acompañado de artífices, lapidarios y arquitectos, a reconocer los restos antiguos descubiertos accidentalmente en Cártama, en la provincia de Málaga; al excavar en el lugar, se hallaron los cimientos de un pórtico y algunas inscripciones y estos resultados excitaron de tal modo la curiosidad del Marqués de Valdeflores que continuó por su cuenta los trabajos durante los años 1751 y 1752, formando una preciosa colección arqueológica parcialmente conservada en la actualidad en el Museo de Málaga. ${ }^{25}$. A nadie debe escapársele que tanto Ensenada como Valdeflores posiblemente trataban de imitar la exitosa búsqueda de obras de arte antiguas que Carlos de Nápoles había iniciado en 1738 en el lugar que entonces se conocía como Portici y que luego se supo que correspondía a una de la ciudades, enterrada por la calamitosa erupción del Vesubio en el año 79, Herculaneum.

Precisamente quien inició esos trabajos fue Roque Joaquín de Alcubierre, otro ingeniero militar y excelente técnico, que comenzó a desenterrar Herculano y Pompeya e inauguró así la moda de les

23 Ch. Duffy, The Military Experience in the Age of Reason, Londres, 1987, pp. 28-40; J. Keegan, A History of Warfare, New York, 1994, p. 344.

24 Vid. H. Capel, J.E. Sánchez y O. Moneada, De Palas a Minerva. La formación científica y la estructura institucional de los ingenieros militares en el siglo XVIII, Madrid, 1988 y Herrero Fernández-Quesada, op.cit. supra nota 12.

25 Los informes del ingeniero al ministro Ensenada fueron publicados por P. Ferrer, Rev. de Archivos, Bibliotecas y Museos 6, 1876, pp. 210-214 y 223-226.

Conimbriga, 40 (2001) 281-317 
Antiques y las gran colección anticuaría de Carlos de Nápoles; sin embargo, estas excavaciones le ganaron a Alcubierre la inquina de los cultos de su época, que llamaban a él y a sus compañeros los piú carnefici dell'Antichitá. ${ }^{26}$ En 1752, Sebastián de Ferignan, Ingeniero

Director de las obras del Arsenal de Cartagena, siguiendo las precisas instrucciones de dar parte de cuantas antigüedades de Cartagena pudiera conocer durante el desempeño de su misión, describió cuidadosamente un pedestal romano insertado en el muro de un edificio afectado por la construcción del nuevo Cuartel de la Marina. ${ }^{27}$ En 1764, el teniente coronel de Ingenieros Carlos Lemaur, encargado del trazado del Camino real de Madrid a La Coruña, comunicó a la superioridad el hallazgo de cinco miliarios romanos durante las obras de refacción del tramo entre Torre del Bierzo y el Manzanal, en la provincia de León. ${ }^{28}$ En 1790, el Conde de Floridablanca comisionó al Ingeniero segundo D. Domingo Valestá "para que busque los medios de averiguar el verdadero sitio en que se dio la célebre batalla de Munda entre César y Pompeyo": el hallazgo de antigüedades antes referido en Cártama y la vecindad de un lugar llamado Monda, amén de una singular interpretación de algunos detalles topográficos del Bellum Hispaniense, pusieron de moda la idea de que la célebre rota de César contra los hijos y partidarios de Pompeyo el Grande ocurrió en las cercanías de la costa malagueña. ${ }^{29}$

26 La bibliografía sobre las excavaciones de las ciudades del Vesubio es ingente, pero la figura de Alcubierre y el papel de Carlos III en el desarrollo de las Altertumswissenschaften ha sido tratada con amplitud por F. Fernández Murga, Roque Joaquín de Alcubierre, descubridor de Herculano, Pompeya y Estabia, Archivo Español de Arqueología, 35, 1962, pp. 3-35 e Id, Carlos III y el descubrimiento de Herculano, Pompeya y Estabia, Salamanca, 1989.

27 El informe de Ferignan al Marqués de la Ensenada se conserva en el Archivo General de Simancas, junto a un preciso dibujo del monumento antiguo, cf. A. Béthencourt, El Marqués de la Ensenada y la arqueología: hallazgos romanos en las obras de cimentación del Arsenal de Cartagena (1750-1752), Boletín del Seminario de Arte y Arqueología de Valladolid 29, 1963, pp. 73-87.

28 Agradezco a Sonia Calle esta noticia, que encontró y copió para mí en el legajo 911, Sección Seer, y Super, de Hacienda, del Archivo General de Simancas. Luego supe gracias a mi buen amigo Julio Encinas Vidal, excelente conocedor por oficio y afición de las antigüedades leonesas, que ya había sido publicada por T. Mañanes, Inscripciones romanas del Bierzo en un documento del siglo XVIII, Boletín del Seminario de Arte y Arqueología de Valladolid 40-41, 1975, pp. 606-612.

29 El encargo de Valestá lo refieren J. y M. Oliver Hurtado, Munda Pompeyana, Madrid 1861, pp. 374-375, según consta en el Archivo Municipal de Osuna; pero en un 
A juzgar por los detalles conocidos, los artilleros del Real Colegio segoviano no diferían en su talante y aficiones de los ingenieros. El propio Somorrostro ofrece varias muestras significativas: Joaquín Ruiz de Porras, mariscal de campo de los Reales Ejércitos y coronel también del Real Cuerpo de Artillería, es descrito como "sujeto de ilustración, que ha viajado por Italia y otros países, hombre dedicado por afición al examen de las obras más considerables de las nobles artes, así antiguas como modernas, y que observó en su juventud y también después de sus viages el acueducto" de Segovia; y la muy sensata y contrastada opinión sobre el origen y la cronología de esa famosa obra civil que el mariscal ofreció al canónigo demuestra la suficiencia de su doctrina y experiencia. $^{30}$ Ruiz de Porras no fue, sin embargo, el único militar en el que Somorrostro encontró ayuda en su empeño anticuario: del oficial artillero Juan López Pinto el canónigo recibió los dibujos de diversas lápidas y esculturas romanas de Segovia, con las que compuso una de las láminas de su libro. Y el coronel del Real Cuerpo de Artillería, Joaquín de Góngora, le proporcionó un dibujo del sotabanco del acueducto donde estaba la cartela con letras y de la que sólo quedaban los agujeros, algunos con restos de plomo y puntas de metal.31 Góngora debió dedicar mucho tiempo al estudio del puente, pues sobre el mismo remitió a la Real Academia de la Historia de Madrid una completa descripción cuyo manuscrito, conservado en el Archivo de la Academia, fue consultado años después por E. Híibner. ${ }^{32}$ Como hizo notar Knapp, cualquiera de esos artilleros $u$ otros conmilitones podría haberse hecho con las tres inscripciones que nos ocupan durante los desplazamientos por España y ultramar impuestos a muchos por las necesidades del servicio y el testimonio de "la relación de 1760" confirma la impresión de que la fundación del Real Colegio de Artillería en 1764 pudo ser la causa directa o indirecta de la llegada de las piezas a Segovia.

Hay, sin embargo, un segundo grupo de candidatos que resultan tan adecuados o más que los artilleros del Alcázar. Desde que en 1721

documento, aún inédito, de la Biblioteca de Palacio, I. Velázquez y yo hemos sabido dos cosas más: los resultados de la exploración de Valestá en las cercanías de Cártama y Monda y que la misión encargada por Floridablanca respondía a una petición de la British Academy para que se averiguara cuál fue el lugar de la última célebre batalla de Julio César.

${ }^{30}$ Somorrostro, op. cit.,p. 43.

31 Somorrostro, op. cit., pp. XI-XII.

32 Vid. CIL II p. 379,prae/, que cita el ms F. 165. 
Felipe V, deseoso de recrear el ambiente de su infancia en un paraje más ameno y menos caluroso que el madrileño, ordenase la construcción del Real Sitio de La Granja de San Ildefonso, la Corte se trasladaba cada verano al fresco paisaje serrano. ${ }^{33}$ Además, enseguida se encontró que el Real Sitio podía servir para más que el descanso estival de los monarcas, pues se convirtió en el lugar ideal para alojar y disfrutar de la colección de antigüedades clásicas que, bajo la influencia y el estímulo de Isabel de Farnesio, los Reyes habían incrementado notablemente con adquisiciones en Italia y en España. De este modo, desde 1725 y hasta principios del siglo XIX, estuvieron en la Real Galería del Palacio de San Ildefonso una extensa serie de estatuas y otras obras de arte clásicas procedentes de las colecciones formadas por Cristina de Suecia, el cardenal Odescalchi, el Marqués de Liche, los Farnesios de Parma y otros príncipes laicos y eclesiásticos renombrados por su afición anticuaría. ${ }^{34}$

La existencia de la Real Galería de San Ildefonso ofrece, pues, la más sencilla explicación para la presencia de tres inscripciones alienae en Segovia: las piezas pertenecían a la colección de la Granja y en cir-

33 Y. Bottineau, Les origines versailleises de La Granja, Versailles. Revue de la Société des Amis de Versailles, 13,3 trimestre 1962, pp. 10-18.

34 E. Aielli e Liscari, Novelle Literarie pubblicate in Firenze Vanno MDCCLI, XII (1751), cols. 303-304: Questa [Real] Galleria [di Santo Ildefonso] o Museo Antiquario è composto del Museo della Regina Cristina di Svezia il quale fu giá comprato dal Re Filippo V, del Museo del Duca dAlba, di parte del Museo Farnesio, che era a Parma, $e$ di altri antichi monumenti raccolti dalle diverse Provinde della Spagna. Cf. A. Ponz, Viage de España, X, Carta V, Madrid, 1787, p. 127. Estudios modernos sobre estas colecciones y su presencia en España: X. de Salas, Compra para España de la colección de antigüedades de Cristina de Suecia, Archivo Español de Arte, 14, 1940-1941, pp. 242-246; O. Neverov, Dai tesori d'arte di Cristina di Svezia, Xenia, 7,1984, pp.77-101; W. A. Blust, Die Antiken-Sammlungen der Kónigin Christina von Schweden, Ruperto-Carola (Zeit. der Vereinigung der Freunde der Studentenschaft der Universitàt Heidelberg), 41, 1967, non vidi. Por la privilegiada posición de su propietario, su estrecha relación con Velázquez y el volumen de obras de arte que contenía, la colección del marqués de Liche (o del Carpió), ha atraído frecuentemente el interés de los estudiosos; una lista de las mismas en R. López Torrijos, Coleccionismo en la época de Velázquez: el marqués de Heliche, en Velázquez y el arte de su tiempo (V Jornadas de Arte del CSIC), Madrid, 1991, pp. 27-36; especial mención, sin embargo, merece el trabajo de B. Caccioti, La collezione del VII Márchese del Carpió tra Roma e Madrid, Bolletino d'Arte, 86-87, 1994, pp. 133-196, donde traza la composición de la misma a partir de los inventarios de las colecciones reales españolas.

Conimbriga, 40 (2001) 281-317 
cunstancias desconocidas pasaron al Real Colegio de Artillería como donativo real. Si eso fue así, queda sobradamente justificada la forastería de las piezas - recuérdese que en San Ildefonso las había también italianas, junto a otras traídas de diversos lugares de España - y el por qué no hay noticias de ellas en el “Anónimo de 1760”| o aún no se había producido el traslado o si se había hecho, el autor de la relación era consciente del origen último de esas lápidas. Pero resulta difícil creer que la cualidad de donativo real hubiera pasado desapercibida a Somorrostro, sobre todo porque sabemos que la mayor parte de los objetos de arte conservados en la Galería Real de la Granja llevaban grabada en lugar visible, y a efectos de testamentaría, una flor de lis o una cruz de Borgoña, que indicaba si su propietario era respectivamente, la Reina o el Rey. ${ }^{35}$

35 La disposición testamentaria de Felipe $\mathrm{V}$ que dio origen al inventario y mareaje de la colección, en G. Anes, Las colecciones reales y la fundación del Museo del Prado, Madrid, 1996, p. 37. Cf. Caccioti, op. cit. supra nota 34, pp. 185 nota 193, 186-187 y 194. Sin embargo, no siempre ha estado claro el significado de estos signos, como lo demuestran las peripecias de CIL VI 3595, un cipo funerario decorado de origen romano que actualmente está en el Museo Arqueológico Nacional de Madrid (inv. 38315) y que Felipe $\mathrm{V}$ compró en la almoneda de la colección Carpió, como demuestra la consabida cruz de Borgoña con la que se la marcó (Caccioti, op. cit., pp. 162-163). Las vicisitudes de esta inscripción desde su hallazgo en Roma a mediados del siglo XVI hasta su actual depósito madrileño han sido recientemente documentadas por S. Perea, Un cipo sepulcral de Roma en Madrid y los doctores-evocad. Nueva interpretación de CIL VI 3595, Gerión 16, 1998, pp. 271-306. Mientras estuvo en el Museo Real (ahora del Prado) fue vista y correctamente identificada por E. Hübner, Die Antike Bildwerke in Madrid, Berlin 1862, p. 153 n. 295 y por R. Ricard, Marbres antiques du Musée du Prado, Bordeaux, 1923, p. 104 n. 172; pero en 1922 fue transferida al Arqueológico Nacional en un canje de objetos entre ambos museos, con tan mala fortuna que la documentación del mismo se traspapeló y en el Prado daban la pieza por perdida, mientras en el MAN nadie sabía su origen; así C. del Rivero, El lapidario del Museo Arqueológico Nacional, Valladolid, 1933, pp. 95-96 n. 353 la atribuye a "procedencia desconocida" y unos años después A. García y Bellido, Esculturas romanas de España y Portugal, Madrid, 1949, I, pp. 319-320 n. 326 amplificó el error suponiéndola "probablemente hallazgo acaedido en España". Pero la confusión alcanzó su cénit cuando P. Piernavieja, primero en un artículo en Archivo Español de Arqueología 43 (1970), pp. 203-212 y luego en su libro Corpus de inscripciones deportivas de la España romana, Madrid, 1977, pp. 157-8 n. 60, identificase al personaje como entrenador de arqueros para el anfiteatro, creando identificó así una nueva e inexistente armatura gladiatoria.

Conimbriga, 40 (2001) 281-317 
Pero ese descarte no agota los posibles vínculos de los epígrafes con el Anticuario de San Ildefonso, pues la migración estival de la Corte indudablemente repercutió en Segovia. ${ }^{36}$ El grupo de artesanos y artistas que construyeron y adornaron el palacio y sus jardines quizá fueron incapaces de imponer en la conservadora ciudad los nuevos gustos estéticos, pero entre ellos hubo ciertamente dilettanti a los que el acueducto $y$, en menor medida, las otras antigüedades locales, debieron llamar poderosamente la atención. Igualmente, haciendo tiempo entre recepciones, antesalas y otras obligaciones de Palacio, hubo cortesanos $y$ otros personajes de alcurnia que encontraron ocasión para acercarse a Segovia y contemplar con sus propios ojos la grande y renombrada arquería antigua, como prueban los múltiples relatos y "vistas" del acueducto dejados por viajeros de la época. ${ }^{37}$

La relación de Segovia con los dilettanti debió intensificarse cuando en 1746, la viuda de Felipe V, sintiéndose incómoda en la vecindad de su hijastro Fernando VI, decidió trasladarse a vivir a La Granja, al menos mientras se construía el nuevo Palacio de Riofrío. Una de las actividades con las que Isabel de Farnesio optó por llenar su tiempo durante ese peculiar exilio fue la catalogación e instalación definitiva de las antigüedades compradas por ella y su difunto esposo, Felipe V; a este fin se rodeó de un grupo de españoles e italianos capaces de ejecutar un proyecto seguramente inspirado en el Museo Farnesio de su natal Parma. Conservamos el relato del "fichaje" de uno de ellos, un monje basiliano de Sicilia, Euticio Ajello y Liscari, según él lo narró en las Novelle Literarie de Florencia: habiendo llegado a Madrid, circa 1740, en el cortejo de la futura esposa del embajador de 3637

36 La relación entre el Real Sitio y Segovia fue, sin embargo, muy complicada, como revela el que Quadrado, en la obra antes señalada (vid. supra n. 10), optase por describir La Granja de San Ildefonso en el volumen destinado a Castilla la Nueva y no junto con Segovia, donde le correspondía según criterios geográficos y administrativos: - [los Reales Sitios] aunque enclavados en el término de Segovia, de la cual apenas distan dos leguas al sudeste, hijuela son de la Corte -y en vez de recibir de la vieja ciudad su animación, a temporadas con su proximidad se la comunican.

37 Un ejemplo lo ofrece la visita, en septiembre de 1806, de la embajadora de Suecia; la excursión acabó en tragedia porque la carroza diplomática volcó al intentar pasar bajo el puente, con grave daño de la señora, que acabó abortando. El incidente lo cuenta Somorrostro, op. cit. p. 71, como causante inmediato de la Real Orden que obligó al derribo de las casas adosadas al monumento, pues además de impedir el tránsito, contribuían a su ruina y lo afeaban.

Conimbriga, 40 (2001) 281-317 
Nápoles en la Corte madrileña, la Reina "avendo saputo Vabilitá di questo Valentuomo, lo chiamó subito appresso di se, e gli diede Vincumbenza di far _un 'essata e copiosa descrizione della magnifica Real Gallería di Santo Ildefonso, che è appunto il luogo, dove ella presentemente soggiornd 1 En el momento de publicarse el informe citado, el basiliano iba por la mitad del trabajo y esperaba terminar su tarea "col fare nuove scoperte per l'illustrazione delVantica Istoria; e col corre gere molto abbagli ed errori presi dagli altrF,38 Este inventario, escrito en forma de dialogo y dirigido a la reina Isabel de Farnesio, existió hasta mediados del siglo XIX en la Primera Secretaría de Estado de Palacio, en Madrid, cuando se le pierde la pista; además, el inventario iba acompañado de una colección de dibujos, el llamado uAlbum Ajello”, que se conserva en el Museo del Prado. ${ }^{39}$

Aunque no consta fehacientemente que Ajello visitara Segovia, hay pocas dudas de que él $u$ otros como él eran los que podían fijarse en las inscripciones existentes en la muralla de la ciudad, leerlas y seguramente, apreciar la peculiar mezcla de romanidad y barbarie que manifiestan. Esa gente disponía de los conocimientos, la afición, los medios y el ennui precisos para recorrer la ciudad y sus muros buscando lápidas romanas, dibujarlas y descifrarlas; sugiero, pues, que entre ellos se busque al anónimo autor del manuscrito epigráfico que Somorrostro empleó con tanta fruición y aprovechamiento.

A imitación de las personas superiores a quienes servían, muchos de estos cortesanos fueron también dilettanti y no limitaron su afición anticuaría a notas y dibujos que luego daban tema de conversación en las tertulias y alimentaban largas discusiones epistolares entre eruditos, sino que formaron también colecciones de antigüedades en las que las inscripciones constituían, si no la parte más preciada estéticamente, sí la de mayor utilidad histórica. Como el valor sentimental de esos conjuntos raramente se sobreponía al precio de las piezas individuales, el

38 Novelle Literarie, cit. supra nota 35. Según Caccioti, op. cit. supra nota 35, ha sido imposible hallar otros datos biográficos sobre este monje siciliano. Respecto a la fecha de su llegada a Madrid, el terminus ante quem es la boda del príncipe de Aci con su prometida Anna Moneada, a la que había acompañado Ajello desde Italia; de nuevo, Cacciotti se declara incapaz de establecerla con certeza pero circa 1740 me parece la más probable.

39 Vd. P. León, en S. F. Schroder, Museo del Prado. Catálogo de la escultura clásica. Volumen I: Los retratos, Madrid, 1993, pp. 15ss; y Caccioti, op. cit., passim. 
destino casi universal de tales colecciones fue la subasta a la muerte de sus primeros propietarios y el incremento del número de antigüedades dislocadas de su contexto y carentes de indicación de procedencia que llenan los museos europeos; en el caso de las colecciones españolas, el hallazgo de las notas de trabajo de un erudito del pasado siglo me ha permitido trazar el origen de cuatro inscripciones del Museo Arqueológico Nacional, que las conservaba sin indicación de procedencia o con ésta confundida; en realidad son de origen romano y los indicios disponibles permiten suponer que llegaron a Madrid formando parte de las colección de alguno de los personajes de origen italiano que sirvieron en una $\mathrm{u}$ otra capacidad en la corte de Felipe $\mathrm{V}$ o de sus hijos; a la muerte de su propietario, las piezas debieron pasar al Real Gabinete de Antigüedades - una práctica muy corriente - y de ahí a la Biblioteca Nacional y luego al Museo Arqueológico Nacional.40

En este punto conviene advertir que algo similar pudo suceder con los tres epígrafes del Alcázar de Segovia, pues los hilos a lo largo de los cuales se ha ido desarrollando mi argumento - la contrastada afición anticuada y coleccionista de algunos personajes de alcurnia vinculados con la Corte y relacionados también con la Academia de Artillería convergen sorprendentemente en la figura de un noble italiano, Felice de Gazzola, Conde de Esparavera, Ceretro-Landi y Macinaso, que en estas tierras fue más conocido por la versión hispanizada de su nombre, Félix Gazola. Miembro de una noble familia de Parma con una larga tradición de servicio a la Corona española, Gazzola vino al mundo en Plasencia de Italia el 21 de octubre de 1698; tenía, pues, 15 años cuando el Tratado de Utrecht transfirió a Austria muchas comarcas de Italia hasta entonces bajo soberanía española. Pero lo que determinó su vida en mayor grado fue el matrimonio de Felipe $\mathrm{V}$ con la heredera del ducado de Parma, Isabel de Farnesio, que acabó cediendo sus derechos sucesorios al primogénito del matrimonio en 1731. Gazzola entró inmediatamente al servicio del nuevo duque Carlos de Borbón, a quien acompañó también en la exitosa campaña que le llevó al trono de la Dos Sicilias. Una vez reconocido en el trono, el nuevo rey de Nápoles nombró a Gazzola Director general del Cuerpo de Artillería y Teniente General de los ejércitos reales. Al ocupar Carlos III el trono de España en 1760, la necesidad de reformar la Artillería real le hizo reclamar la

40 Cuatro inscripciones urbanas en el Museo Arqueológico Nacional de Madrid, en preparación.

Conimbriga, 40 (2001) 281-317 
venida de Gazzola, que llegó a Madrid a finales de Agosto y al poco presentó al monarca un proyecto de actuación que fue aprobado un año después, al tiempo que su promotor era nombrado Teniente General de los Ejércitos $\mathrm{y}$, poco después, Inspector general del Real Cuerpo de Artillería; con ese encargó, Gazzola participó en 1762 en la guerra contra Portugal, que fue su última campaña como soldado en activo. Precisamente tal servicio retrasó la puesta en marcha del proyecto más fecundo y duradero de la reforma de la Artillería de Su Majestad, la fundación del Real Colegio del Arma, del que saldrían los nuevos oficiales que gobernarían el Cuerpo según el nuevo espíritu de eficacia y servicio a la Corona imaginado por Gazzola. Tras diversas vicisitudes, se decidió emplazar el nuevo Colegio militar en el Alcázar de Segovia, que abrió sus puertas el 18 de mayo de 1764.41 Gazzola consagró a esta institución los últimos años de su vida, organizando la docencia y seleccionando a alumnos y profesores. El italiano murió en Madrid el 4 de mayo de 1780, a los 82 años de edad. ${ }^{42}$

Si por la fundación del Real Colegio Gazzola merece una nota a pie de página en la Historia de España, no menos es digno de ella por su poco conocida, pero más interesante a nuestros efectos, intervención en el desarrollo de las Ciencias de la Antigüedad. Según parece, durante su servicio a Carlos de Borbón en Nápoles, las partidas de caza del rey en las marismas y bosques del golfo de Salerno, llevaron a Gazzola a visitar las espectaculares minas existentes cerca de la desembocadura del río Salso, prontamente identificadas con la antigua ciudad de Paestum. ${ }^{43}$ Debido a que la malaria se había apoderado del litoral de

41 F. Lanuza, Para la historia del Colegio de Artillería de Segovia, Estudios Segovianos, 18, 1966, pp. 61-76; Herrero Fernández-Quesada, op. cit. supra nota 12, pp.78-85.

42 No parece existir una completa biografía del Conde Gazzola. Lógicamente, su relación con el Real Colegio de Artillería ha despertado la atención de los historiadores militares españoles, vd. F. Lanuza, El Conde de Gazola y el Colegio de Artillería de Segovia (documentos inéditos), Segovia, 1966. Quien últimamente se ha ocupado del personaje ha sido J. Pérez Villanueva, con motivo de su ingreso en la Academia de San Femando, vid. El conde Félix Gazzola. Primer director del Real Colegio de Artillería de Segovia, Segovia, 1987; El italiano Felice Gazzola en la Ilustración española (Discurso del académico electo leído en el acto de su Recepción Pública el 25 de enero de 1987 y contestación del Excmo. Sr. D. José Hernández Díaz), Madrid, 1987; y Un Italiano en Segovia. Félix Gazzola, fundador de la Academia de Artillería, s.l. (Segovia?), s.d.

43 Sobre los monumentos de ese lugar, vd. F. Krauss, Die grieschichen Tempel (3. erweiterte Aufl.), Berlín, 1976; P. Zancani Montuoro y U. Zanotti Bianco, Heraion

Conimbriga, 40 (2001) 281-317 
la zona, el lugar era de difícil acceso y la arena y la maleza cubrían las ruinas. Estas circunstancias permitieron que, salvo algunos expolios para construir la catedral de Salerno y otros edificios de Amalfi, el lugar pasase desapercibido incluso durante el Renacimiento, preservando de este modo el alzado casi completo de tres templos muy antiguos y de otros edificios de más cercana data. ${ }^{44}$ Entre 1745 y 1750, Gazzola patrocinó un generoso proyecto de planimetría, limpieza y restauración de las ruinas en el que trabajaron Francisco Sabattini, el arquitecto de Carlos III, que levantó la topografía del lugar; Gian Battista Natali y Antonio Magri, que dibujaron los templos $y$ otros edificios antiguos; y Bertolozzi, que realizó los primeros grabados del lugar. ${ }^{45}$

A pesar de su cercanía a las recién descubiertas ciudades enterradas del Vesubio, las mismas circunstancias que habían preservado las ruinas impedían el fácil acceso y Paestum tardó en convertirse en parada obligada del Grand Tour de dilettanti y eruditos. En 1750, Gazzola invitó a J. G. Soufflot, el más famoso de los arquitectos franceses del momento, a visitar el lugar, donde realizó algunos dibujos; una decena de años después, acudió Winckelmann y como Soufflot, no dejó de sorprenderse de la escasa atención que habían recibido los monumentos más antiguos, en los que él no tardó en descubrir un compendio de la historia de la arquitectura griega.

alia foce del Sele, vol. I y II, Roma, 1951-1954; E. Greco y D. Theodorescu, Poseidonia-Paestum, Roma, 1980-1985; y J. G. Pedley, Paestum. Greeks and Roman in Southern Italy, Londres, 1990.

44 Según parece, los templos se convirtieron en una referencia topográfica destacada para la navegación y como tal aparecen en cartas de marear a partir del siglo XVII; hay también noticias de que en 1734 un arquitecto napolitano, F. Sanfelice, presentó a Carlos III un proyecto para reciclar materiales de las ruinas de Paestum en la construcción del palacio de Capodimonti, vid. Pedley, op. cit. p. 168.

45 La cuestión de la historia del descubrimiento de Paestum ha sido estudiada y dictaminada, vid S. Lang, The Early Publications of the Temples at Paestum, Journal of the Warburg and Courtauld Institute, 12, 1950, pp. 48-64; y D. Mustilli, Prime memorie suile rovine di Paestum, en Studi in onore di Riccardo Filangeri, III, Nápoles, 1959, pp. 105-121. En consecuencia y aunque hubo indudablemente quien visitó y describió las ruinas antes de 1745 , se le reconoce a Gazzola el mérito del descubrimiento y publicación de las primeras noticias sobre Paestum, vd. G. Mora, Historias de mármol. La arqueología clásica española en el siglo XVIII (Anejos de AEspA, 18), Madrid, 1998, pp. 116-119 y E. Gran-Aymerich, Naissance de lArcheologie moderne, París, 1998, p.26.

Conimbriga, 40 (2001) 281-317 
Quizá por ello mismo, la publicación en 1764 de un libro de Soufflot con vistas de esos edificios - algunas suyas, otras regaladas por Gazzola -, constituyó un éxito instantáneo, convirtiendo Paestum en un topos de la imaginación romántica. Nada extraño, pues, que Th. Major editase casi inmediatamente en Londres otro libro de estampas que alcanzó tanta difusión como el Soufflot e incitó a otras empresas parecidas. La proliferación de obras de dudosa calidad e información deficiente fue lo que seguramente decidió a Gazzola a encargar al Padre Paoli que diera a conocer los trabajos realizados en Paestum entre 1745 y 1750; ese libro, titulado Rovine delia città di Pesto detta ancora Posidonia, ya no lo vio el conde pues fue publicado en Nápoles en 1784 y su edición la pagó Carlos III, constituyendo, sin duda, un precioso homenaje postumo a un buen súbdito y fiel colaborador. ${ }^{46}$

El origen italiano de Gazzola, sus largos años de servicio en Nápoles, sus trabajos en el descubrimiento de Paestum, su probada afición por los libros, grabados y objetos relacionados con la Antigüedad y su relación fundacional con la Academia de Artillería lo señalan, $a$, como el candidato ideal que pudo aportar al Colegio militar las tres inscripciones a las que él $u$ otros quizá dieron valor docente, bien por su antigüedad, bien por estar realizadas en mármoles singulares, que es posiblemente la explicación más simple para su presencia en el Gabinete de Mineralogía del Laboratorio de Química.

Desgraciadamente, y como pasa muchas veces, se echa de menos la prueba fehaciente que redondee el argumento aquí desarrollado. En este caso, sin embargo, he estado en un tris de lograrla, porque Gazzola, soltero y sin descendientes directos, manifestó en última voluntad que su patrimonio debía servir para constituir en Piacenza una fundación encargada de la educación de huérfanos y huérfanas jóvenes. ${ }^{47}$ Para llevar a cabo esta manda testamentaria, pocos días después de la muerte del noble italiano, se procedió al inventario de las tres casas que, por

46 La referencia a la bibliografía más antigua se encuentra en F. Furchhein, Bibliographie der Insel Capri und der Sorrento Halbinsel, sowie von Amalfi, Salerno und Paestum, Leipzig, 1916 (2a ed.), pp. 124 y ss., que puede actualizarse con la obra de J. Bérard, Bibliographie topographique des principaux citées grecques, París, 1941, pp. 79ss y las citas recogidas por P. Zancani-Montuoro en el artículo correspondiente de la Enciclopedia dell'Arte Antica, Roma, 1963, s.v. Paestum.

47 Esta institución bicentenária aún existe y con las mismas finalidades estipuladas por su fundador, vid. F. Arisi, 11 Gazzola (1781-1981), Piacenza, 1981 ( vidi).

Conimbriga, 40 (2001) 281-317 
razón de oficio y dignidad, mantenía abiertas en Piacenza, Madrid y Segovia. Esos inventarios, junto al expediente personal del conde en el Ejército español y sus testamentos, forman un abultado legajo que se conserva en el Archivo Central Militar de Segovia y permanecen mayormente inéditos, a pesar de que Pérez Villanueva optó por convertir las últimas voluntades de Gazzola en el tema de su discurso de ingreso académico; a este fin reprodujo las partes más destacadas del inventario testamentario, especialmente en lo relacionado con la biblioteca del noble italiano. ${ }^{48}$

Del examen del inventario de las posesiones de Gazzola, Pérez Villanueva concluyó que su gusto por la Antigüedad le define como un hombre muy de su tiempo. Medallas, antigüedades de Roma, los sepulcros antiguos, el anfiteatro Flavio, una curiosa descripción, con dibujos al apoyo, del traslado e instalación del obelisco egipcio de San Pedro...Fiel a sus vocaciones primeras, entre sus libros de estampas vemos uno bien significativo: "El libro de estampas que trata de las ruina de la ciudad de Paestum”, y de otras ilustres antigüedades próximas, como Puzzoli 49 La afición anticuaría se ve confirmada por algunos de los objetos existentes en la casa madrileña de Gazzola, la más rica y completa de las tres; en ella, los albaceas encontraron un camafeo de ágata, de tres colores, que lleva esculpida una cabeza de mujer con ropaje griego ... una sortija de ágata con mujer desnuda "sentada, y con una sábana, como saliendo del baño”; en otro camafeo aparece un busto de mujer "con ropaje griego”,50 Había además, esculturas que por su descripción parecen antiguas o hechas a imitación de las antiguas: una de marfil representaba la historia de Andrómeda; a falta de la figura de Perseo, se nos precisa. Otra representaba a Venus y Cupido. El Hermafrodita estaba representado en marfil ... dos centauros de bronce, otra escultura de un gladiador, y otra de Baco ... .51

Descripciones así nos dejan a oscuras sobre la calidad, procedencia e incluso, la edad de las piezas; pero quienes estén acostumbrados al manejo de inventarios saben que sus entradas suelen ser más vagas y

48 La documentación sobre Gazzola depositada en el Archivo General Militar de Segovia se encuentra en su 9a Sección, legajo G-148. Cf. los trabajos de Pérez Villanueva citados en nota 43.

49 Pérez Villanueva, El conde Félix de Gazzola....cit. supra, p. 36.

50 Ibid. p. 51.

51 Ibid. pp. 56-57.

Conimbriga, 40 (2001) 281-317 
menos claras de lo que nos gustaría. ${ }^{52}$ Pérez Villanueva ya notó el contraste entre la precisa descripción de los libros que formaban la biblioteca de Gazzola y los parcos datos con los que se listaron las más de 250 pinturas que formaban la colección del noble italiano: apenas se reseña el tamaño de los cuadros, su tasación $\mathrm{y}$, en algunos casos patentes, su tema. El hecho es doblemente lamentable porque resulta imposible individualizar los cuadros y sus autores; sólo en dos ocasiones, los albaceas mencionan firmas pero éstas no son otras que las de Rubens y Van Dyck, por lo que hay razones más que sobradas para sospechar que Gazzola pudo haberse hecho con una variada e importante pinacoteca; por la época en que vivió y la gente que trató, concluye Pérez Villanueva, no sería extraño que tuviera lienzos y dibujos de otros autores de mérito que trabajaron esos años en la Corte de Madrid: Mengs, Tiépolo y Goya. ${ }^{53}$ Frente al genérico listado de la colección pictórica, los albaceas fueron precisos hasta el escrúpulo en el inventario de la biblioteca, pormenorizando cuidadosamente el nombre de los autores, los títulos, el año de edición y el formato de cada libro, de tal modo que Pérez Villanueva, aún sin esforzarse demasiado, fue capaz de obtener un esbozo de los gustos de lectura del fundador del Real Colegio de Artillería. ${ }^{54}$

A pesar de que parece haber trascrito completamente el legajo testamentario, Pérez Villanueva sólo reprodujo extractos de aquellas partes conformes con sus intereses. Nada dice de inscripciones antiguas y el somero y rápido examen del dossier no me ha permitido identificar

52 Vd. Y. Bottineau, Les inventaires royaux et l'histoire de l'art: l'exemple de l'Espagne 1666-1746, Information d'Histoire de VArt, 4, 1959, pp. 30-45. Compárese, a este respecto, las descripciones de piezas antiguas contenidas en los inventarios de Felipe V e Isabel de Farnesio (Caccioti, art. cit. supra nota 34 y G. Anes, op.cit. supra nota 35) o el más extenso, pero igual de impreciso, de su hijo Carlos III, vd. F. Fernández Miranda y Lozana, Inventarios reales. Carlos III. 1789-1790, Madrid, 1988-1989, passim.

52 El carácter cosmopolita del arte en la Corte española del siglo XVIII es resaltado por Y. Bottineau en la Introducción al catálogo de El Arte europeo en la Corte de España durante el siglo XVIII, Madrid 1980, pp. 15-20, una esplendida exposición hispano-francesa (Burdeos y París, mayo-diciembre de 1979; Madrid, febrero-abril de 1980), y en la que pudo comprobarse hasta qué punto los Borbones convirtieron la corte madrileña en un foco de atracción para artistas foráneos, especialmente italianos y franceses.

54 Pérez Villanueva, El conde Félix de Gazzola....cit. , pp. 76-88.

Conimbriga, 40 (2001) 281-317 
con certeza referencia alguna de las tres lápidas que Somorrostro vio treinta años después en el Laboratorio de Química del Alcázar. Este silencio, sin embargo, no necesariamente invalida la hipótesis aquí formulada porque las inscripciones pudieron haber sido transferidas al Alcázar antes de la muerte de Gazzola. Que no debe descartarse la posibilidad de una donación inter vivos, lo avala la circunstancia de que, a la muerte del conde, en su casa segoviana sólo se encontraron los objetos propios del ajuar doméstico; tan desprovista debía de estar la casa que una nota de la propia testamentaría advierte que dos meses después de la apertura del remate, nadie había acudido aún a él, de tal modo que todo acabó siendo comprado por el conde de Lacy, Comandante General del Real Cuerpo de Artillería y Director del Real Colegio del Arma. ${ }^{55}$

\section{Sobre el origen y desaparición de las piedras.}

Resulta, pues, que fueron muchos los que tuvieron la oportunidad, la afición y los medios necesarios para llevar a Segovia las piedras. Nada se ha dicho hasta ahora, sin embargo, sobre la procedencia original de los epígrafes, quizá porque la circunstancia de que las inscripciones estén en paradero desconocido parece prejuzgar que la única respuesta posible es non liquet: los parcos comentarios de Somorrostro omiten cualquier dato indicativo y no cabe examinar las piedras para determinar las canteras de origen. Por eso, lo más simple quizá es dejarse llevar por la personalidad y el curriculum vitae de sus anónimos propietarios: si fueron cortesanos o militares españoles, resulta lógico suponer que las piezas provenían de algún lugar de la Península Ibérica, aunque las vicisitudes diplomáticas y bélicas de esos años no descartan por completo otras procedencias. $\mathrm{Si}$, por el contrario, las inscripciones pertenecieron a cualquiera de los muchos italianos - incluido Gazzola - al servicio de la Corona española, parece preferible suponerlas de origen itálico, lo que justificaría la onomástica de uno de los personajes nombrados y la elaborada forma de expresar la edad de los difuntos; pero tampoco debe desecharse el origen ibérico porque cualquier vero dilettante seguramente también se sintió atraído por las antigüedades locales.

55 Ibid. pp. 41-42.

Conimbriga, 40 (2001) 281-317 
Creo, sin embargo, que al menos dos de las inscripciones de la Academia de Artillería de Segovia eran hispanas y, más específicamente, de origen hético o lusitano. Baso mi aserto en que en ambas se combina la invocación a los Manes (dis Manibus) con la fórmula sepulcral hic situs est sit tibi terra levis. Es bien conocido que la aparición o la ausencia de una determinada fórmula es un indicio frecuentemente empleado para datar las inscripciones; tal sucede, por ejemplo, con la mención en los epitafios de los dioses infernales, cuya popularización se fecha en el s. II d.C. ${ }^{56}$ Pero en ese caso y otros similares, las fórmulas se consideran individualmente y lo que aquí tomo en consideración no es la singularidad del uso de una u otra sino, por el contrario, el empleo conjunto de $d m s+h s e+s t t l$, resulta ser un rasgo endémico, y casi exclusivo, de las inscripciones de Hispania.

Es una desgracia que el estudio regional de las combinaciones de fórmulas no haya despertado aún la atención que merece y que, en consecuencia, los editores de los corpora epigráficos, cuando llega el momento de confeccionar los índices, listan las fórmulas aisladamente, sin caer en la cuenta de que la conjunción de determinadas locuciones resulta tan significativa como el uso individual de cada uno de sus elementos. Ese desmembramiento de los índices dificulta documentar con rapidez y eficacia la hipótesis aquí planteada, porque hacerlo exhaustivamente y sin sombra de dudas obligaría a revisar una a una todas las inscripciones de varias provincias, una tarea que supera ampliamente los límites de este trabajo y la paciencia de quien lo escribe pero que, sin duda alguna, constituye la mejor revalida de lo aquí expresado.

Sin embargo, quizá no sea preciso a la postre acudir a una encuesta de esa envergadura; por un lado, basta abrir al azar las colecciones epigráficas de algunas regiones hispanas para comprobar hasta que punto prevaleció en estas tierras el uso conjunto de la invocación a los Manes y de la fórmula sepulcral hic situs est sit tibi terra levis. ${ }^{51}$ Por otro, el necesario control y comparación con las prácticas imperantes en

56 Una útil síntesis del uso de estas tres fórmulas en la epigrafía hispana - con referencias a otros lugares en Knapp, op. cit. supra nota 4, pp. 356-368.

57 Una buena muestra, aún geográficamente parcial, es la que ofrecen los tres fascículos publicados de la nueva edición de CIL II, correspondientes a los conventus Cordubensis, Astigitanus y la parte meridional del Tarraconensis. Si se quiere, en cambio, una mayor representatividad geográfica, confróntense los índices de los seis fascículos de HEp, que cubren las novedades y hallazgos producidos en el último decenio. 
otras provincias puede hacerse empleando las dos bases datos en formato digital que, sin ser exhaustivas, contienen tal número epígrafes que pueden considerarse una muestra significativa. ${ }^{\mathbf{5 8}}$

Los resultados son apabullantes. En Roma, sólo hay una decena de ejemplos del uso, pero uno de ellos es el epitafio de una sierva de un consular de muy posible origen hispano y cuyo contubernalis se llama justamente, Celtiber; del resto es difícil determinar si se trata también de personajes de origen hispano.59 En Ostia, sólo he podido documentar dos epitafios pero, de nuevo, uno perteneció a un lusitano muerto lejos de su tierra $\mathrm{y}$ al que sus deudos enterraron empleando el ritual y las fórmulas característicos de su tierra; el otro es un militar cuya origo no se especifica. ${ }^{60}$ He encontrado también dos casos más en Mesia, para los cuales aún carezco de explicación. ${ }^{61}$ Fuera de las provincias

58 Me refiero a las empresas impulsadas por el Prof. Alfóldy en Heidelberg y el Prof. Clauss en Frankfurt, y cuyas respectivas URLs se indicaron en nota 13. Estimo que, en total, habré examinado unas 60000 inscripciones, desigualmente repartidas entre las provincias del Imperio. En lo que respecta a la ciudad de Roma, he empleado el índice de palabras en contexto preparado por el prof. Jory y sus colaboradores para CIL VI. En todos los casos, sólo he considerado aquellas inscripciones en las que se emplean, sin asomo de dudas, las dos fórmulas; no se han tenido en cuenta, por lo tanto, los epitafios mutilados ni los de lectura controvertida.

59 CIL VI 12025, 13062, 14092, 14727, 16224, 17064, 17930, 19372, 22979, 23494, 25013, 26288 y 27881. Del grupo, sólo he podido comprobar de visu CIL VI 12025. actualmente en los Museos Capitolinos (G. L. Gregori. y M. Mattei, Supplementa Italica-Imagines (Supplementi fotografici ai volumini italiani del CIL): Roma (CIL VI) I: Musei Capitolini, Roma 1999, n. 402), cuya forma nada tiene que ver con las aras de Segovia. En CIL VI 27881 se menciona precisamente a los dos miembros de la familia de L. Antistius Rusticus y Mummia Nigrina, cuyas origines hispanas parecen evidentes, vid. PIR ${ }^{2}$ A 765; Rusticus fue cónsul en época de Domiciano y la inscripción se data con precisión en el 87. El posible origen hispano de los demás difuntos del grupo es difícil de establecer, por tratarse de nombres muy corrientes; es lástima que el epitafio de C. Puppius Restitutus, ex provincia Baetica, civitate Baesariensi (CIL VI 38809), sólo cumpla parcialmente los requisitos de la búsqueda, pues la fórmula sepulcral H.S.E.S.T.T.L, no va acompañada por la invocación a los dioses Manes.

60 CIL XIV. 3632 = Inserit IV,1,165 (un veterano de la coh. lilipr.) y CIL XIV, 4822: D. M. / M. Caesius / Maximus / Aeminiensis / annor. XXVI / h. s. e. s. t. t. I.

61 AE 1972, 533 = A. Sãsêl y J. Sãsêl, Inscriptiones Latinae quae in Iugoslavia inter annos MCMLX et MCMLXX repertae et editae sunt. Accedunt nonnullae ad annos MCMXL-MCLXpertinentes (Situla. Diss. Musei nationalis Labacensis, 19), Ljubljana, 1978, 564 = P. Petro vie, Inscriptions de la Mésie Supérieure, IV : Naissus. Remessiana . Horreum Margi, Belgrado 1979, 120. AE 1934, 179 = M. Mirkovic y S. Dusanic, 
hispanas, la única concentración de epitafios de estas características se encuentra en el Norte de África, donde hay casos aislados en lugares de Argelia y Túnez, $^{62}$ y mucho más frecuentes en las comarcas que hoy forman Marruecos, lo que no resulta sorprendente considerando la proximidad a Hispania y las relaciones de todo tipo que siempre han existido entre ambas orillas del Estrecho de Gibraltar. ${ }^{63}$

Dentro de Hispania, el uso que nos interesa no se documenta con igual intensidad en todas las zonas. La provincia donde estuvo más de moda fue la Bética; aunque no he tenido ni el tiempo ni la inclinación suficiente para revisar detalladamente por comarcas la extensión del manierismo y determinar si la intensidad de su empleo dibuja un mapa significativo, me he guiado por el examen de los corpora regionales, que cada vez son más numerosos y completos. La mayor fiabilidad la ofrecen, como es lógico, los dos fascículos héticos de la nueva edición de CIL II, los correspondientes a los conventus Astigitanus ${ }^{64}$ y

A primera vista, al menos, no parece haber diferencia con el resto de la provincia, pues la conjunción de la invocación a los Manes y la fórmula sepulcral h.s.e.s.t.t.l. fue igualmente popular en Itálica, en las tierras

Inscriptions de la Mésie Supérieure, I: Singidunum et le nord-ouest de la province, Belgrado, 1976, 52.

62 CIL VIII, $5361=17468=\mathrm{S}$. Gsell, Inscriptions latines de l'Algerie, I: Inscriptions de la Proconsulaire, París, 1922, 463. CIL 08, $27108=$ M. Khanoussi y L. Maurin, Dougga (Thugga). Études épigraphiques, París, 1997, 150.

63 M. Euzenat, J. Marion y J. Gascou, Inscriptions antiques du Maroc, 2: Inscriptions latines, París 1982, 10,12, 14-15, 17, 22, 31-32, 56, 70, 256, 537,547 y 607.

64 CIL 11/2-5,6,11,13-14,18,21,29,32,40,41,43-46,50,53,81,86,102,108, $114,119-120,125,136,158,160,162,192,200,233,246,258,261,271,277,279-$ $-282,285,289,317,319,333,339,345,348-349,381,398,446,451,517,524,529$, $548-549,563,570,598,603-604,609,640,643,669-700,703,707,716,722,724-725$, 727-728, 734, 759, 763, 765, 810, 832, 860-861, 869, 881, 883, 899, 916, 920, 925, $931,937,942-943,951,957,964,967-969,972,974,991,993,998,1006,1008-1009$, $1011,1054,1117,1144,1176,1186,1193-1194,1203,1208 \mathrm{a}, 1214,1222-1223,1226$, $1233,1239,1243,1245,1250,1287,1289,1293,1314,1342-1343$ у 1346.

65 CIL II/2-7, 8a, 10, 13, 21,25-25a, 52, 64, 111, 117-118, 157-158, 178, 183, 201, 309, 328, 336, 344, 386, 390+392, 401,410, 418, 423-424, 426, 430-431,433, 436, 449, 451, 472, 476, 481, 484, 493-494, 496-497, 500, 502, 507, 512, 514, 519, 521, 528a-529, 531, 533, 535-536, 538, 541-542, 548-549, 553-554, 559-561， 567, 709, 711-712, 721, 731, 738-739, 762, 781, 795, 818, 846, 900, 945, 966, 987, 991, 993-994 y 1011.

Conimbriga, 40 (2001) 281-317 
que ahora forman la provincia de Sevilla, ${ }^{66}$ en la comarca extremeña que se conoció como Baeturia, ${ }^{67}$ y en las ciudades antiguas ahora englobadas en la moderna provincia de Granada. ${ }^{68}$

Ya fuera de los límites de la provincia Bética, la práctica siguió viva y boyante en los lugares pertenecientes al conventus Pacensis ${ }^{69}$, siendo especialmente popular en la capital de la Lusitania, Augusta Emerita. ${ }^{70} \mathrm{~A}$ partir de aquí, el uso se difumina cuanto más se progresa hacia el Norte, de tal forma que el empleo conjunto de las fórmulas es ocasional incluso en Turgalium, tan vinculado a la capital provincial, ${ }^{71}$

66 Para facilitar la consulta ofrezco la referencia a CIL II de aquella inscripciones incluidas en ese corpus; en cambio, para aquellas otras aparecidas con posterioridad refiero únicamente al orden de J. González Fernández, Corpus de inscripciones latinas de Andalucía, vol. II:Sevilla, Sevilla, 1991-1996 (aquí abreviado CILA). Las concordancias entre ambos corpora pueden encontrarse al final de cada uno de los volúmenes pares de CILA. CIL II490*= 5363,1045,1077,1078,1079,1080,1081,1088,1137,1140,1142$-1143,1146-1148$ (p. 836), 1156, 1158, 1198, 1202, 1203, 1204, 1206, 1207, 1209 (p. 698), 1216, 1218, 1224, 1225,1228,1231,1234, 1236 (p. 841), 1237,1238 (p. 841), $1239 \quad$ (p. 841), 1246,1247,1248,1265,1272,1289,1291,1292,1296,1298,1373,1377, $1393,1402,1419$ (p. 851), 1420,2292,2332 y 2336,5038,5040,5377-5379,5390,5392, 5395-5397,5410,5421,5437,6281-6282 y 6380. CILA 85,109,111-112,121,126,175, $177-178,181-182,190-191,193,196,213,248-249,251,254,267,269,301,306,312$, $315-316,413,418-419,422,424,428,430,432,434,455,459,461,465,467-470,472$, 474-476,481-482,492-493,495,596, 602, 832,1001 у 1005 .

67 A.M. Canto, Epigrafia romana de la Beturia Céltica, Madrid, 1997, nn. 5, 13, 23bis, $48=$ CIL II 977; $68=$ CIL II 5357; $71=$ CIL II 999; $78=$ CIL II 985; $101=$ CIL II 998; $114=$ CIL II 1029 (p. 836); 115, 121, $124=$ CIL II 1032; $128=$ CIL II 1033; $148=$ CIL II 979; 162, $166=$ CIL II 966; $167=$ CIL II 965; $168=$ CIL II 967; 167, 182, 183, $184=$ HEp 4, 993; $189=$ CIL II 968; $192=$ CIL II 969; 194, 200, 209 $=$ CIL II 971; 210-211 y 216. Debo a J.V. Madruga una prolija relación de las inscripciones extremeñas en que se emplea la combinación de fórmulas.

68 M. Pastor Muñoz y A. Mendoza, Inscripciones latinas de la provincia de Granada, Granada, 1987, nn. 1,30, 57, 81,84, 90-92, 101 y 123.

66 j. d’Encamaçâo, Inscrições romanas do Conventus Pacensis , Coimbra, 1984, nn. 14,16,19,22-23,39-44,47,52-54,64-65,69,72,81-82,87,99-100,102,107-110, 112 , $114-115,134,152,195,208-210,212-216,218,220-221,248,250-251,253-254$, 257-258, 260-264, 266, 274-275, 277, 298-299, 304-305, 307-313, 318-319, 331-336, 346 a $-347,350,354-355, \quad 357,385,388-389,391,394-395,398-399,408,415,418-419$, $426,431,433,435,443,447,450,464-466,468,470,582,593,595^{\text {a }}$.

70 CIL II 489, 490, 491,495-496, 497-499, 501,505, 506, 508, 509, 510, 513, $516,518,522,523,524,551,577,5258,5270$ y 5272 .

71 CIL II 624 y H. Gimeno y A.U. Stylow, Juan Pérez Holguin y la epigrafía trujillana, Veleta, 10, 1993 pp. 117-177, nn. 13, 22 у 61.

Conimbriga, 40 (2001) 281-317 
y, por supuesto, en Norba, Capara y Conimbriga; ${ }^{72}$ la presencia de este ejemplo septentrional ayuda a explicar la lápida del Aeminiensis enterrado en Ostia, al que se ha hecho referencia antes, y también la presencia de otros dos casos en la Galaecia, ya en la provincia Citerior. ${ }^{73}$ Por el oriente, esta costumbre bética se notó aún menos; en la orla marítima mediterránea, desde Cartago Nova a Tarraco, apenas hay una media docena de $\operatorname{casos}^{74}$ mientras que en el interior, la conjunción de fórmulas sólo se encuentra en algunos lugares donde la proximidad y las fuertes vinculaciones con el valle fluvial hicieron sentir, de modo especial, la influencia bética ${ }^{75}$

Es claro, por lo tanto, que el origen de la práctica de conjugar la invocación a los Manes con la fórmula sepulcral hic situs est sit tibi terra levis debe buscarse en la Bética, que es donde con mayor frecuencia e intensidad se documenta. En este sentido, conviene recordar que ya hace algún tiempo, Stylow ${ }^{76} 77$ hizo notar que, a pesar de la communis opinio que sostiene que la invocación a los Manes no hizo su aparición en provincias antes del s. II d.C., un epitafio cordobés fechado con precisión el primer día de Agosto del 19 a.C., contiene la locución Dei Manes receperunt illam 77 Al mismo tiempo, llamaba la atención sobre otra peculiaridad bética, un pequeño grupo de aras funerarias de mediados del s. I. d.C., que fueron primeramente identificadas como conjunto por Gamer, ${ }^{78}$ y que según Stylow, parecen haber servido al doble propósito de dar culto a los dioses infernales y de iden-

72 CIL II 751 (Norba); CIL II 827, 837 y 839 (Capera); CIL II 388 = J. Alarcão y R. Etienne, Fouilles de Conimbriga II: épigraphie et sculpture, París, 1976, n. 66 (Conimbriga).

73 CIL II 2548-2549, de Iria Flavia.

74 Carthago Nova: CIL II 3464 y 5944 y Abascal y Ramallo, op. cit. supra nota 16, n. 169; nótese la observación de estos autores, quienes sospechan que los tres casos mencionados corresponden quizá a alieni, Tarraco: CIL II 4366 y $6087=$ Alfóldy, $o p$. cit. supra nota $16, \mathrm{nn} .184$ y 579 .

75 CIL II 3235, 3243-3245, 3261, 3332, 3344, 3355, 3357, 3362-3363, 3368, 3372 y 3374.

76 Stylow, art. cit. supra nota 18, p. 223.

77 CIL II/2-7 397 = II 2255: C(aio) Sentio Saturnino) co(n)s(ule) / K(alendis) Sextilib(us) / Dei Manes / receperunt / Abulliam N(umeri) l(ibertam) / Nigellam. Nótese que en Roma, el caso más antiguo de uso de D. M. S. es, según Degrassi, CIL VI 7303 (= ILS 7863).

78 G. Gamer, Formen rómischer Altare auf der Hispanischen Halbinsel, Maguncia, 1989, pp. 130 y ss.

Conimbriga, 40 (2001) 281-317 
tificar la cenizas del difunto: en la práctica, el epitafio se grabó precisamente en el zócalo hiperdesarrollado de esos altares. ${ }^{79}$ No sólo se trataría, pues, de los ejemplos más tempranos del uso formulario conjunto que nos ha ocupado hasta ahora, sino que es posible que resida en ellos el origen de la costumbre de invocar a los dioses Manes a la vez que se señala el lugar de la tumba y se desea al difunto que repose en paz.

El más que probable origen bético o emeritense de las piedras del Alcázar, no determina, sin embargo, las circunstancias de su traslado, aunque hay una posible y lógica explicación. En 1751, dentro de los planes de reforma del Ejército real del Marqués de la Ensenada, se fundaron en Barcelona y Cádiz sendas Escuelas teóricas para el Cuerpo General de Artillería, que siguieron existiendo hasta la apertura del Real Colegio de Segovia. ${ }^{80}$ Fuera de su testamento y de algunas anécdotas reveladoras de la gran confianza que le dispensó el Rey, es realmente poco lo que se sabe de las actividades de Gazzola durante los veinte años de residencia en España. Pero a tenor de la correspondencia que cruzó con el Ministro de la Guerra en los prolegómenos de la fundación del Colegio de Artillería, ${ }^{81}$ se desprende que debió de viajar extensivamente por el país, siquiera para visitar las instituciones militares existentes y elegir el lugar donde iba instalarse la nueva. No he conseguido documentar fehacientemente las etapas de esos viajes, pero Herrero encontró en la documentación guardada en Simancas, una serie de cartas de Gazzola a sus superiores en las que solicitaba el traslado de distintos efectos de las suprimidas Escuelas de Barcelona y Cádiz al Colegio de Artillería que iba a inaugurarse a los pocos meses; ${ }^{\mathbf{8 2}}$ de la selección que hace, parece claro que el conde tuvo un conocimiento de visu de ambos lugares. Supongo pues, que de este modo pudieron llegar a Segovia las piedras que vio Somorrostro, bien porque estaban ya en la Escuela de Cádiz cuando ésta se suprimió, bien porque Gazzola pudo adquirirlas en uno de sus viajes por Andalucía.

Y para finalizar, la última cuestión: ¿qué fue de la inscripciones vistas por Somorrostro?. Poco cierto puede decirse al respecto: que se

79 Stylow, art.cit. supra, p. 226.

80 Vid. F. Gil Ossorio, Las reformas artilleras del Conde de Gazola, Revista de Historia Militar, 31, 1971 p. 85 y Herrero Fernández-Quesada, op. cit. supra nota 12, pp. 52-64.

81 Archivo General de Simancas, Guerra moderna, legajo 560.

82 Herrero, op. cit., pp. 183-184.

Conimbriga, 40 (2001) 281-317 
trasladaran cuando la Academia de Artillería mudó su sede a consecuencia del incendio es, sin duda, una posibilidad, pero entonces debe explicarse por qué no consta en esa institución el paradero de las piedras. Por otro lado, según la opinión de los peritos a los que he consultado, es muy probable que las inscripciones se extraviasen como consecuencia de los variados usos a los que se destinó la Casa de la Química tras el incendio del Alcázar y la marcha de la Academia de Artillería: cárcel, almacén, cuartel de la Guardia Civil, hospital de sangre y, últimamente, Archivo militar.

\section{En conclusion}

En las páginas anteriores, he señalado todas las razones por las que creo probado que Knapp se equivocó considerando de origen local las tres lápidas que Somorrostro vio a comienzos del siglo XIX en dependencias del Colegio de Artillería de Segovia. No sólo hay argumentos en las propias piedras - su forma y el material del soporte, la onomástica de los difuntos y las fórmulas empleadas en el epitafio -, que así lo indican, sino que es muy posible que ésas no estuvieran en la ciudad cuando el anónimo autor del "manuscrito de 1760 " compuso su relación. Además, se ha resaltado suficientemente cómo, de lo escrito por Somorrostro, se desprende que éste tenía claro que no eran piezas segovianas.

En esa tesitura, creo haber demostrado que, entre 1760 y 1820 , no faltaron personas que pudieron hacerse con lápidas antiguas de otros lugares de Hispania o Italia y depositarlas, en circunstancias imprecisas, en el Real Colegio de Artillería, posiblemente con intención pedagógica. Tanto los propios militares allí destinados como los cortesanos de La Granja e, incluso, el mismísimo fundador de la Academia militar, eran dignos discípulos de la Aufklarung contemporánea y seguramente compartían en mayor o menor medida la idea de que el saber tenía inmediatas repercusiones beneficiosas para la Humanidad. Además, se movían en un ambiente en el que la afición por las "antiguallas" era un modo agradable y distinguido de contribuir al Fomento del país; ser dilettanti era signo indudable de distinción social, pues no debe olvidarse que el coleccionismo anticuario estuvo muy de moda entre los miembros de la Familia Real española del siglo XVIII. 
Por último, pienso que también he conseguido despejar la incógnita de la procedencia de al menos dos de la piedras en discusión, cuyo formulario las identifica como de origen hético o emeritense. Indudablemente, esto no es una prueba irrefutable pero al menos aporta algo de luz a lo que parecía un enigma sin solución.

Es posible, pues, que lo que Somorrostro vio en las dependencias del viejo castillo no fueran a la postre espectros y que su presencia y desaparición puedan justificarse con prosaicas razones. Pero no deja de parecerme que todo el enredo conserva un cierto aire paranormal, siquiera por la presciencia del canónigo segoviano, que afirmó que tales piedras "desaparecerán y no quedará mas memoria de ellas que la que se da en esta colección".

\section{APÉNDICE I}

D.M. S.

$\mathrm{C}^{\circ}$ IVLIANO. ANN. XV

IVL $^{a}$ HEI. PIS. MATER

FIL. PIENTISSIMO. P. C.

H.S.E.S.T.T.L.

A Cayo Juliano, de quince años, hijo piado sis simo, su madre Julia.

Se hallan estas dos lápidas en el gabinete de mineralogia del laboratorio quimico del Real Cuerpo de Artillería, establecido en esta ciudad, y ademas un pedestalito de marmol para una cabeza, que dice: c. IVLV COAAAAAA : is. v- A I.S.

TTT a

Conimbriga, 40 (2001) 281-317 
APÉNDICE II

Concordancia de las inscripciones segovianas

\begin{tabular}{|c|c|c|c|c|}
\hline $\begin{array}{l}\text { COLMENARES } \\
\text { (PAG.) }\end{array}$ & $\begin{array}{c}\text { ANÓNIMO } \\
1760\end{array}$ & SOMORROSTRO & CIL II & KNAPP \\
\hline 22 & 1 & 1 & 2731 & 227 \\
\hline 25 & 2 & 2 & 2756 & 283 \\
\hline 16 & 3 & 3 & 2750 & 260 \\
\hline \multirow[t]{9}{*}{33} & 4 & 4 & 2747 & 255 \\
\hline & 5 & 5 & 2732 & 228 \\
\hline & 6 & 6 & 2744 & 250 \\
\hline & 7 & 7 & 2746 & 252 \\
\hline & 8 & 8 & 2733 & 226 \\
\hline & 9 & 9 & 2738 & 240 \\
\hline & 10 & 10 & 2737 & 238 \\
\hline & 11 & 11 & 2740 & 241 \\
\hline & 12 & 12 & 2739 & 261 \\
\hline \multirow[t]{21}{*}{24} & 13 & 13 & 2745 & 251 \\
\hline & 14 & 14 & 2734 & 229 \\
\hline & 15 & 15 & 2742 & 245 \\
\hline & 16 & 16 & 2751 & 259 \\
\hline & 17 & 17 & 2760 & 246 \\
\hline & 18 & 18 & 2557 & 257 \\
\hline & 19 & 19 & 2754 & 264 \\
\hline & 20 & 20 & 2748 & 256 \\
\hline & 21 & 21 & 2730 & 225 \\
\hline & & 22 & 2752 & 263 \\
\hline & & 23 & 2729 & 224 \\
\hline & & 24 & 2743 & 249 \\
\hline & & 25 & 2755 & 266 \\
\hline & & 26 & 2749 & 258 \\
\hline & & 27 & 2735 & 237 \\
\hline & & 28 & 2759 & 267 \\
\hline & & 29 & 2741 & 230 \\
\hline & & 30 & 2753 & 265 \\
\hline & & Apéndice $12 \mathrm{n}$. II & & 242 \\
\hline & & Apéndice 12 n. I & & 247 \\
\hline & & Apéndice $12 \mathrm{n}$. II bis & & 248 \\
\hline
\end{tabular}

Conimbriga, 40 (2001) 281-317 